\title{
Preparation, Characterization and Voltammetric Aspects of a Silsesquioxane Organofunctionalized With Imidazole Groups and Subsequent Reaction With Silver and Potassium Hexacyanoferrate
} (III)

\author{
Tayla Fernanda Serantoni da Silveira ${ }^{1}$, Maiara de Souza Magossi ${ }^{1}$, Mariana de Souza Magossi ${ }^{1}$, Urquisa de \\ Oliveira Bicalho ${ }^{1} \&$ Devaney Ribeiro do Carmo ${ }^{1}$ \\ ${ }^{1}$ Faculdade de Engenharia de Ilha Solteira UNESP - Universidade Estadual Paulista, Ilha Solteira, Brazil \\ Correspondence: Devaney Ribeiro do Carmo, Faculdade de Engenharia de Ilha Solteira UNESP - Universidade \\ Estadual Paulista, Departamento de Física e Química, Av. Brasil Centro, 56. CEP 15385-000, Ilha Solteira, SP, \\ Brazil. Tel: 55-18-3742-1029. E-mail: docarmo@dfq.feis.unesp.br
}

Received: February 19, 2014 Accepted: March 25, 2014 Online Published: April 14, 2014

doi:10.5539/ijc.v6n2p34

URL: http://dx.doi.org/10.5539/ijc.v6n2p34

\begin{abstract}
This paper describes the interaction of a octa (3-chloropropyl)octasilsesquioxane (SS) functionalized with imidazole (SSI) groups, and its subsequent reaction with silver (AgSSI) and hexacyanoferrate (III) (AgHSSI). The materials SS, SSI were characterized by infrared (FTIR); solid state ${ }^{13} \mathrm{C}$ and ${ }^{29} \mathrm{Si}$ nuclear magnetic resonance (NMR). The AgSSI and AgHSSI were characterized by electronic (Uv-Vis) and infrared spectroscopy (FTIR). The AgHSSI was incorporated into a graphite paste electrode and the electrochemical studies were conducted with cyclic voltammetry. The AgSSI system was studied first, followed by the AgHSSI. The spectroscopic studies reveals that preparation was conducted with success. The cyclic voltammogram of AgSSI obtained from a graphite paste electrode modified $(50 \% \mathrm{~m} / \mathrm{m})$ exhibited a redox couple with average potential $\left(\mathrm{E}^{\theta^{\prime}}\right)$ of $0.01 \mathrm{~V}$ (vs $\mathrm{Ag} / \mathrm{AgCl}_{(\mathrm{s})}, \mathrm{KNO}_{3}, 1.0 \mathrm{~mol} \mathrm{~L}{ }^{-1} ; v=20 \mathrm{mV} \mathrm{s}{ }^{-1}$ ), attributed to the $\mathrm{Ag}^{0} / \mathrm{Ag}^{+}$redox process. The cyclic voltammogram of AgHSSI with AgHSSI $(50 \% \mathrm{~m} / \mathrm{m})$ exhibited a single redox couple, much wider with $\mathrm{E}^{\theta^{\prime}}=0.14$ $\mathrm{V},\left(v s \mathrm{Ag} / \mathrm{AgCl}_{(\mathrm{s})}, \mathrm{KNO}_{3}, 1.0 \mathrm{~mol} \mathrm{~L}^{-1}, v=20 \mathrm{mV} \mathrm{s}^{-1}\right)$ attributed to the $\mathrm{Fe}^{2+}(\mathrm{CN})_{6} / \mathrm{Fe}^{3+}(\mathrm{CN})_{6}$ process.
\end{abstract}

Keywords: silsesquioxane, imidazole, silver, potassium hexacyanoferrate (iii), voltammetry

\section{Introduction}

Polyhedral oligosilsesquioxanes (POSS) refer to all structures that have the empirical formula $\left(\mathrm{RSiO}_{1,5}\right)_{\mathrm{n}}$, where $\mathrm{R}$ can be a hydrogen or any organic group such as alkyl, methyl, aryl, vinyl, phenyl, arylene, or any organofunctional derivative thereof, $\mathrm{n}$ can vary between 4 and 30, but it is usually 6, 8, 10 and 12 (Cordes, Lickiss, \& Rataboul, 2010; Lickiss \& Rataboul, 2008; Voronkov \& Lavrent'yev, 1982). Silsesquioxanes (POSS) are a class of nanomaterials with great potential in the field of nanoscience and nanotechnology. The interest in the properties of silsesquioxanes has been the subject of research in various companies and universities in the development of new materials, what can be observed with the substantial increase in the number of patents and publications related to these materials (Phillips, Haddad, \& Tomczak, 2004).

Due to the highly symmetrical three-dimensional nature of their nucleus, POSS are good precursors for the production of hybrid organic-inorganic materials (Dutkiewicz, Maciejewski, \& Marciniec, 2009; Gnanasekaran, Madhavan, \& Reddy, 2009; Skaria \& Schricker, 2010). They are also used as catalysts (Dutkiewicz, Maciejewski, \& Marciniec, 2009; Fina et al., 2006), dendrimic precursors (Dutkiewicz, Maciejewski, \& Marciniec, 2009; Ropartz, Morris, Foster, \& Cole-Hamilton, 2002), polymer precursors (Pielichowski, Njuguna, Janowski, \& Pielichowski, 2006), biocompatible materials, and as precursors for developing liquid crystals (Lin \& Chen, 2010), homogeneous and heterogeneous catalysis (Fina et al., 2006; Abbenhuis, 2000), electroactive films (Morán, Casado, \& Cuadrado, 1993), additives (Devaux, Rochery, \& Bourbigot, 2002; Wann et al., 2008), antibacterials and biocides (Chojnowski et al., 2006), and are also used in thin films and coatings for various applications, including nanocomposites (Ro, Park, Soles, \& Yoon, 2010; Silveira, Silvestrini, Bicalho, \& Do Carmo, 2013).

The electrochemical field has few studies on modified silsesquioxanes as substrates, acting as electron mediators 
or electrochemical sensors. It is known that after specific chemical modification the large-surface area nanostructured materials contain metal centers, hence powerful catalysts and electrocatalysts. Imidazole, due to the presence of nitrogen donor atoms, can coordinate with a variety of transition metal ions (Joseph, Ramamurthy, \& Subramanian, 2011; Yin, Xu, Qu, Zhao, \& Sun, 2010). It is has long been known that imidazole has a particular affinity for electrophilic silanes (Bassindale, Codina-Barrios, Frascione, \& Taylor, 2008). Thus, materials prepared using silica-based substrates functionalized with imidazole are suitable for the sorption of toxic heavy metals, such as mercury and copper. Therefore silsesquioxanes are potential candidates for organofunctionalization with imidazole groups. When compared with silica gel, the advantage of using silsesquioxanes modified by covalent attachment of organofunctional groups regards their easy preparation, high sorption capacity and fast adsorption kinetics, in addition to their good chemical stability (Rajec \& Hanzel, 2003; Silveira, 2012). Within this context, particularly our interest in the silsesquioxane chemistry is to prepare multifunctional nanostructured materials that can be used as electrochemical sensors. A preliminary characterization the SSI was publish recently (Silveira, Silvestrini, Bicalho, \& Do Carmo, 2013). Based on our interest above mentioned, in this paper we present the preparation, and a complementary characterization and voltammetric study of interaction of a octa-(3-chloropropyl)octasilsesquioxane (SS) functionalised with imidazol (SSI) groups, and its subsequent reaction with silver (AgSSI) and hexacyanoferrate (III) (AgHSSI). The electrochemical behavior of AgHSSI provide additional information about different species formed during their preparation.

\section{Experimental}

\subsection{Reagents and Solutions}

Unless specially state all reagents solutions and supporting electrolytes were prepared using Milli-Q water and the reagents and solvents were of analytical grade (Merck or Aldrich) and were used as purchased.

\subsection{Techniques}

\subsubsection{Diffuse Reflectance}

The diffuse reflectance spectra of the bulk solid binuclear complex were recorded between 350 and $1000 \mathrm{~nm}$ on a Guided Wave model 260 spectrophotometer, using a tungsten-halogen lamp as the radiation source, and detectors of $\mathrm{Si}$ and $\mathrm{Ge}$.

\subsubsection{Fourier Transform Infrared Spectra}

The FTIR spectra were recorded on a Nicolet 5DXB FTIR spectrometer. About $150 \mathrm{mg}$ of $\mathrm{KBr}$ were ground in a mortar and a sufficient quantity of the solid sample was ground with $\mathrm{KBr}$ to produce a $1 \mathrm{wt} \%$ mixture resulting in pellets. The data collection a minimum of 64 scans was collected for each sample at a resolution of $\pm 4 \mathrm{~cm}^{-1}$ in the range 4000 to $400 \mathrm{~cm}^{-1}$.

\subsubsection{NMR Solid State Analyses}

All ${ }^{29} \mathrm{Si} \mathrm{NMR} \mathrm{(59.5} \mathrm{MHz)} \mathrm{and}{ }^{13} \mathrm{C}$ NMR $(75.4 \mathrm{MHz})$ solid state analyses were recorded on a Varian INOVA 300 spectrometer. The samples were packed in zirconia rotors and spun at the magic angle at $4500 \mathrm{~Hz}$, after relaxation delay of $10.0 \mathrm{~s}$ and $6.0 \mathrm{~s}$ for ${ }^{29} \mathrm{Si}$ and ${ }^{13} \mathrm{C}$ respectively. All chemical shifts are reported in units (ppm) using tetramethylsilane (TMS) as external reference.

\subsubsection{Electrochemical Measurements}

Cyclic voltammograms were performed using the Microquimica (MQP1-PGST) potentiostat. The three electrode systems used in these studies consisted of a modified working electrode (graphite paste electrode) an $\mathrm{Ag} / \mathrm{AgCl}(\mathrm{s})$ reference electrode, and a platinum wire as the auxiliary electrode. The measurements were carried out at $25^{\circ} \mathrm{C}$.

\subsection{Synthesis of Octa-(3-chloropropyl)octasilsesquioxane (SS)}

For the synthesis of octa-(3-chloropropyl)silsesquioxane (SS) a procedure following as described in the literature (Chojnowski et al., 2006; Silveira, Silvestrini, Bicalho, \& Do Carmo, 2013) after minor modifications. $800 \mathrm{ml}$ of methanol, $27 \mathrm{ml}$ of hydrochloric acid $(\mathrm{HCl})$ and $43 \mathrm{~mL}$ of 3-chloropropyliltriethoxysilane were added into a round bottom flask of $1000 \mathrm{~mL}$. The system was kept under constant stirring at room temperature for 6 weeks. The solid phase was separated by filtration in a sintered plate funnel, yielding a white solid, octa-(3-chloropropyl)octasilsesquioxane (SS), which was then oven dried at $120^{\circ} \mathrm{C}$ for 4 hours. Figure 1 (A) illustrates a representative scheme of this synthesis. 
A

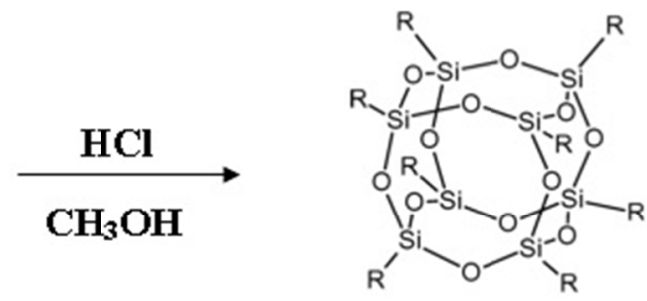

\section{$\mathrm{R}=\mathrm{CH}_{2} \mathrm{CH}_{2} \mathrm{CH}_{2} \mathrm{Cl}$}

\section{B}<smiles>ClCCC[Si]12O[Si]3(CCCl)O[Si]4(CCCl)O[Si](CCCCl)(O1)O[Si]1(CCCCl)O[Si](CCCCl)(O4)O[Si](CCCCl)(O3)O[Si](CCCCl)(O2)O1</smiles>

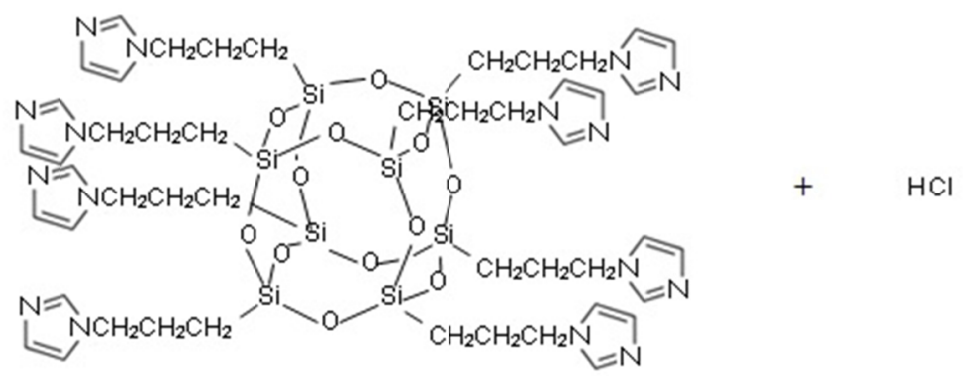

Figure 1. (A) Schematic representation of the preparation of octa-(3chloropropyl)silsesquioxane and (B) organofunctionalization of octa-(3-chloropropyl)octasilsesquioxane (SS) with the modifying agent imidazole

$[18,24]$

\subsection{Functionalization of Octa-(3-chloropropyl)octasilsesquioxane With Imidazole}

The functionalization of octa-(3-chloropropyl)octasilsesquioxane (SS) was performed in a 3-neck flask of 500 $\mathrm{mL}$ containing $10 \mathrm{~g}\left(9.7 \times 10^{-3} \mathrm{~mol}\right)$ of SS, previously dried at $100{ }^{\circ} \mathrm{C}$ for 2 hours, $5.923 \mathrm{~g}\left(8.7 \times 10^{-2} \mathrm{~mol}\right)$ of imidazole and approximately $200 \mathrm{~mL}$ of dimethylformamide (DMF). The mixture was refluxed at $160{ }^{\circ} \mathrm{C}$ with constant stirring for 96 hours. Then the solid plate was separated in a sintered funnel and washed in a Soxhlet extractor with DMF for 48 hours. The material obtained was oven dried $100{ }^{\circ} \mathrm{C}$ for 4 hours and described as SSI. Figure 1(B) schematically illustrates the organofunctionalization process of SS with imidazole.

\subsection{Formation of Complex AgHSSI}

The AgHSSI complexes were prepared as follows: $1.0 \mathrm{~g}$ of SSI was added to $25 \mathrm{~mL}$ of a solution of silver nitrate $1.0 \times 10^{-3} \mathrm{~mol} \mathrm{~L}^{-1}$. The mixture was stirred for $1 \mathrm{~h}$ at room temperature. The solid phase was then filtered and washed thoroughly with deionized water. The materials resulting from this first phase were oven dried at $70{ }^{\circ} \mathrm{C}$ and designated as AGSSI. In the second stage, the AgSSI was added to a solution of $1.0 \times 10^{-3} \mathrm{~mol} \mathrm{~L}^{-1}$ of potassium hexacyanoferrate (III) and the mixture was stirred for $1 \mathrm{~h}$ at room temperature and then the solid was thoroughly filtered, washed with deionized water and dried at $70{ }^{\circ} \mathrm{C}$. The materials resulting from this stage were described by AgHSSI.

\subsection{Preparation of the Graphite Paste Electrode Modified With AgHSSI}

The graphite paste electrode modified with AgHSSI was prepared by mixing $50 \mathrm{mg}$ of CdHSSI with $50 \mathrm{mg}$ of 
graphite (Aldrich) and $50 \mu \mathrm{L}$ of mineral oil. The electrode body was produced from a glass tube of $3 \mathrm{~mm}$ i.d. and $14 \mathrm{~cm}$ height, containing graphite paste. A copper wire was inserted through the opposite end of the glass tube to establish electrical contact. After homogenizing the mixture, the modified paste was carefully positioned on the tube tip to avoid possible air gaps, which often enhances electrode resistance. The external surface of the electrode was smoothed on soft paper. A new surface can be produced by scraping out the old surface and replacing the graphite paste.

\section{Results and Discussion}

\subsection{Visible Spectroscopy (Diffuse Reflectance UV-Vis.)}

Figures 2(A) and (B) illustrate the visible-ultraviolet spectroscopy (diffuse reflectance UV-Vis) of the AgHSSI and SSI species, respectively. The AgHSSI spectrum verified the existence of a high energy peak at around 427 $\mathrm{nm}$. After spectral deconvolution, the presence of three absorptions with maximum wavelengths $\left(\lambda_{\max }\right)$ at around 405, 432 and $509 \mathrm{~nm}$ (A) was found. These bands are related to the ligand to metal charge transfer (LMCT) of $\left[\mathrm{Fe}^{\mathrm{III}}(\mathrm{CN})_{6}\right]^{3-}$ (Figgis \& Hitchman, 2000) and metal to metal (MMCT), respectively.

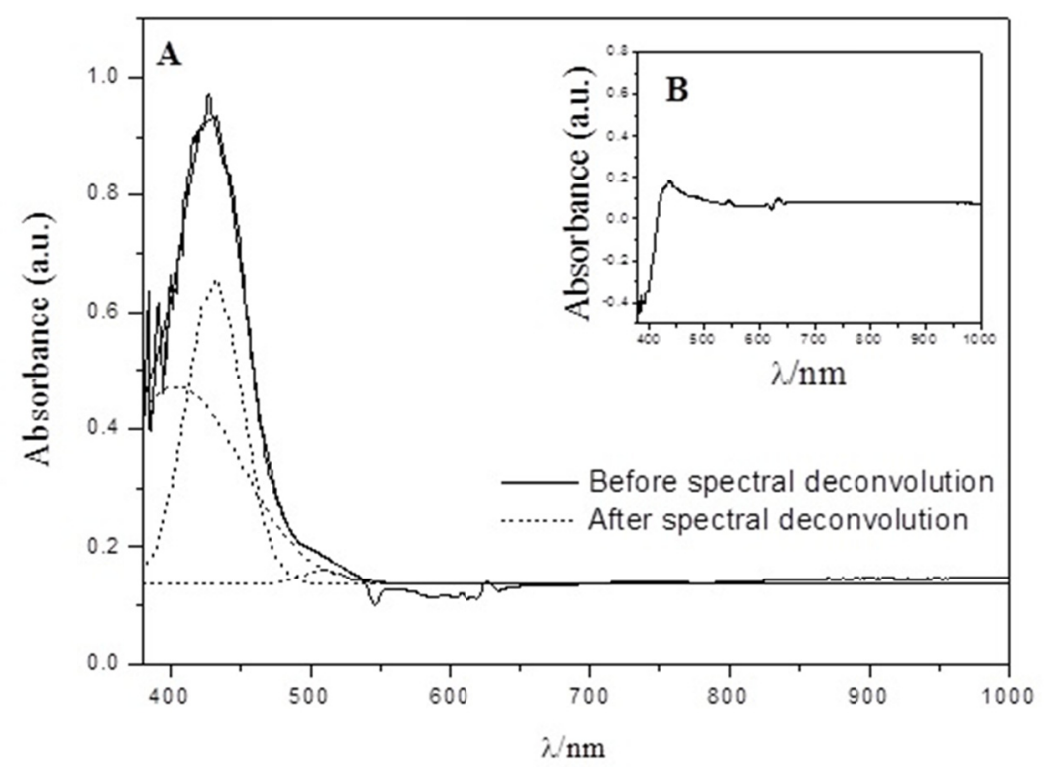

Figure 2. Ultraviolet visible spectroscopy (diffuse reflectance UV-Vis) of: (A) AgHSSI and (B) SSI

\subsection{Vibrational Spectroscopy of SSI and AgHSSI}

The vibrational spectrum of octa-(3-chloropropyl)octasilsesquioxane (SS), as illustrated in Figure 3(A), showed an absorption band at about $1110 \mathrm{~cm}^{-1}$ which is a typical band of the material, as it regards $\mathrm{Si}-\mathrm{O}-\mathrm{Si}_{(\mathrm{Si}-\mathrm{O}-\mathrm{Si})}$ stretching which corresponds to the cage-shaped structure of SS. Two other one absorption bands were observed at around $700 \mathrm{~cm}^{-1}$, attributed to deformation of the $\mathrm{C}-\mathrm{Cl}_{(\mathrm{C}-\mathrm{Cl})}$ bond, and the other at around $2950 \mathrm{~cm}^{-1}$ related to the axial deformation of the $\mathrm{C}-\mathrm{H}_{(\mathrm{C}-\mathrm{H})}$ bond (Silverstein \& Welbster, 1996; Do Carmo, Paim, Dias Filho, \& Stradiotto, 2007).

Figure 3(B) and (C) illustrate the vibrational spectra of imidazole and the functionalized materials (SSI), respectively. Figure 3(B) refers to the vibrational spectrum of the imidazole ligand, and exhibits characteristic bands of this compound such as the bands ranging from 500 to $1700 \mathrm{~cm}^{-1}$, related to the axial deformation vibrations of the imidazole ring bonds. The bands in the region between 1400 and $1700 \mathrm{~cm}^{-1}$ correspond to the axial deformation of the $\mathrm{C}=\mathrm{C}_{(v \mathrm{C}=\mathrm{C})}, \mathrm{C}-\mathrm{N}_{(\mathrm{v} C-\mathrm{N})}$ and $\mathrm{C}=\mathrm{N}_{(\mathrm{v} C=\mathrm{N})}$ bonds in the cycle. In the region between 3200 and $3500 \mathrm{~cm}^{-1}$ the bands observed were attributed to the axial deformation of $\mathrm{N}-\mathrm{H}_{(\mathrm{v}-\mathrm{H})}$, these bands probably overlap the bands attributed to the axial deformation of $\mathrm{C}_{-} \mathrm{H}_{(\mathrm{v} C-\mathrm{H})}$ ring bonds (Silverstein \& Welbster, 1996). 


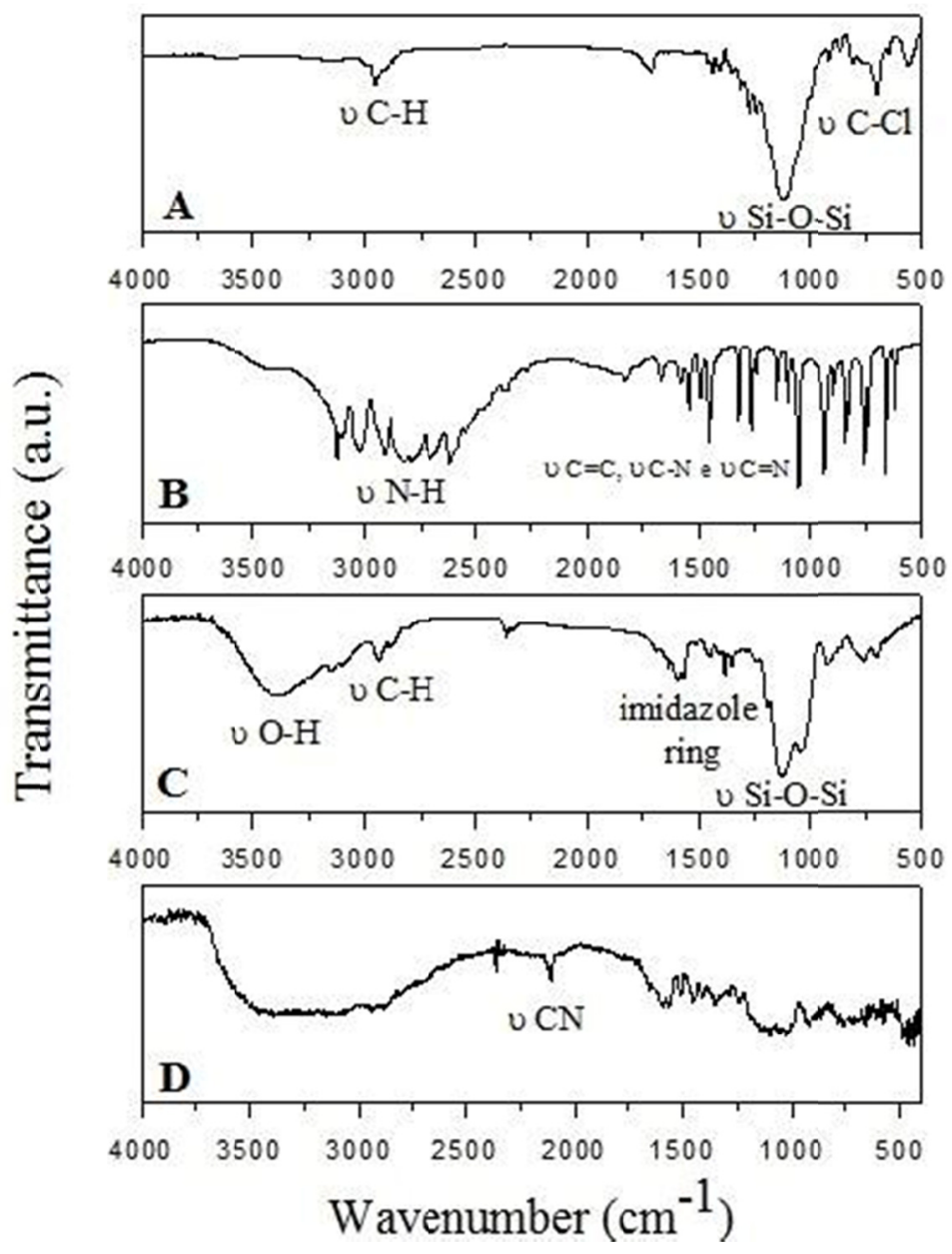

Figure 3. Vibrational spectra in the infrared region: (A) SS, (B) Imidazole, (C) SSI and (D) AgHSSI

Characteristic absorption bands of the precursor materials were observed in the spectrum shown by SSI (Figure $3 \mathrm{C})$. The band at about $1120 \mathrm{~cm}^{-1}$ is related to the $\mathrm{Si}-\mathrm{O}-\mathrm{Si}(\mathrm{Si-O}-\mathrm{Si})$ stretching corresponding to the cage-shaped structure of silsesquioxane, suggesting that the cubic structure of this matrix also held. The other bands observed in the region between 2800 and $3200 \mathrm{~cm}^{-1}$ are attributed to the axial deformation of the $\mathrm{C}-\mathrm{H}_{(\mathrm{C}-\mathrm{H})}$ bonds, in both precursors. The broad and intense band between 3200 and $3600 \mathrm{~cm}^{-1}$ was attributed to the axial deformation of $\mathrm{O}-\mathrm{H}_{(\mathrm{O}-\mathrm{H})}$ of the remaining water molecules. The bands between 1300 and $1530 \mathrm{~cm}^{-1}$ were attributed to the vibrations of the axial deformation of the imidazole ring bonds (Silverstein \& Welbster, 1996), which were relatively intense. A decrease of the band at around $700 \mathrm{~cm}^{-1}$ was also observed, related to the $\mathrm{C}$-Cl vibrations of SS, thus evidencing its partial functionalization and suggesting that not all peripheral groups reacted with the imidazole ligand.

As previously stated, the spectrum exhibited by potassium hexacyanoferrate(III) (A) shows significant vibrations at $\sim 2112$ and $2030 \mathrm{~cm}^{-1}$, which are related to the vibrations of the $\mathrm{C} \equiv \mathrm{N}_{(v \mathrm{C} \equiv \mathrm{N})}$ bond.

The spectra exhibited by AgHSSI (D) showed typical vibrations of its precursors at $\sim 1100 \mathrm{~cm}^{-1}$ attributed to the $\mathrm{Si}-\mathrm{O}-\mathrm{Si}_{(v \mathrm{Si}-\mathrm{O}-\mathrm{Si})}$ stretching corresponding to the cage-shaped structure of SS, and the region between 1300 and 1530 $\mathrm{cm}^{-1}$ attributed to the axial deformation of the imidazole ring bonds. Additionally, the spectra showed vibrations at $2105 \mathrm{~cm}^{-1}$ related to $\left.\mathrm{C} \equiv \mathrm{N}_{(\mathrm{v}} \mathrm{C} \equiv \mathrm{N}\right)$ stretching, which is characteristic of the potassium hexacyanoferrate (III) precursor (Silverstein \& Welbster, 1996).

\subsection{Nuclear Magnetic Resonance for SSI}

The Figure 4 illustrates the solid state ${ }^{13} \mathrm{C}$ NMR spectra for SS (A) and SSI (B). Three resonances peaks at 10.57; 27.82; $48.02 \mathrm{ppm}$ were observed for the solid state ${ }^{13} \mathrm{C}$ NMR spectra for $\mathrm{S}$, attributed to the carbon atoms $\mathrm{CH}_{2} \underline{\mathrm{C}} \mathrm{H}_{2} \mathrm{Si}, \mathrm{CH}_{2} \mathrm{CH}_{2} \mathrm{CH}_{2}, \mathrm{ClCH}_{2} \mathrm{CH}_{2}$ of the propyl group (aliphatic chain) present in SS. In the solid state ${ }^{13} \mathrm{C}$ NMR spectra for SSI, five resonance peaks were observed at $9.58 ; 26.46,64.38 \mathrm{ppm}$, attributed to the carbon 


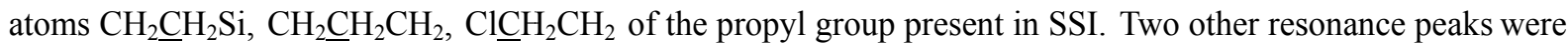
observed at $137.34 ; 123.18 \mathrm{ppm}$, and these are attributed to the carbon atoms of the imidazole ligand (Henderson, Shepherd, \& Abolaf, 1986; Aany Sofia et al., 2009).
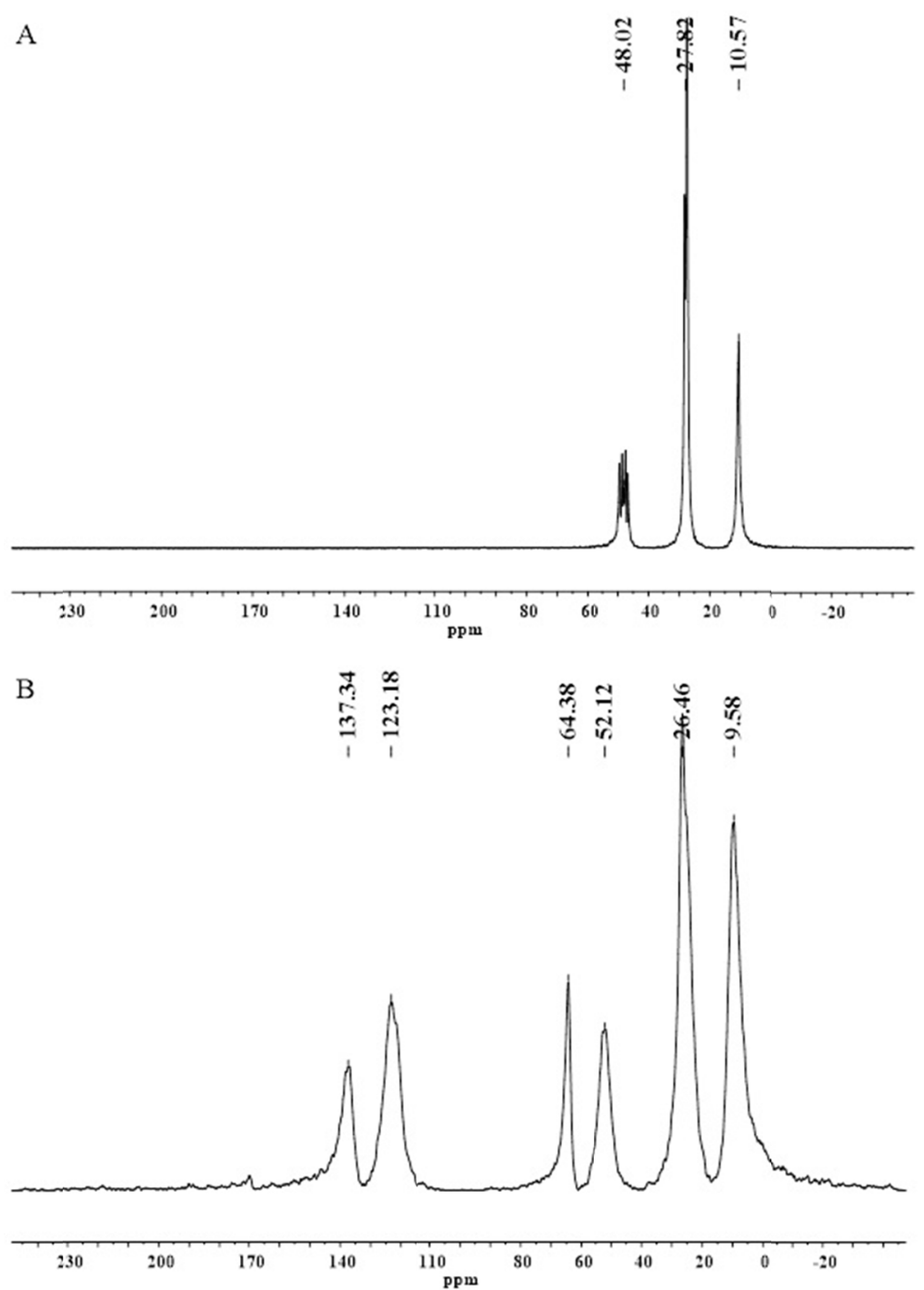

Figure 4. Solid state NMR of ${ }^{13} \mathrm{C}$ for SS (A) and SSI (B)

The resonance observed at $52.12 \mathrm{ppm}$ is a strong indication that not all peripheral groups of the cube were functionalized with imidazole. The solid state ${ }^{29} \mathrm{Si}$ NMR spectra of SS and SSI are illustrated in Figure 5(A) and (B). The solid state ${ }^{29} \mathrm{Si}$ NMR of SS showed only one resonance at $67.42 \mathrm{ppm}$, corresponding to silicon (Si-O-Si) (Dutkiewicz, Maciejewski, \& Marciniec, 2009; Marciniec, Dutkiewicz, Maciejewski, \& Kubicki, 2008).

However, two resonance peaks were observed for SSI, one at 59.69 and another at $70.58 \mathrm{ppm}$, also suggesting that not all peripheral groups of the cubes were imidazole-ligated during the functionalization process of octa-(3-chloropropyl)octasilsesquioxane. This behavior is not very clear, but two factors may have contributed to this: i) the positive charge repulsion exhibited by the imidazolium ring, ii) steric effect provided by the electrons contained in the imidazole groups. 

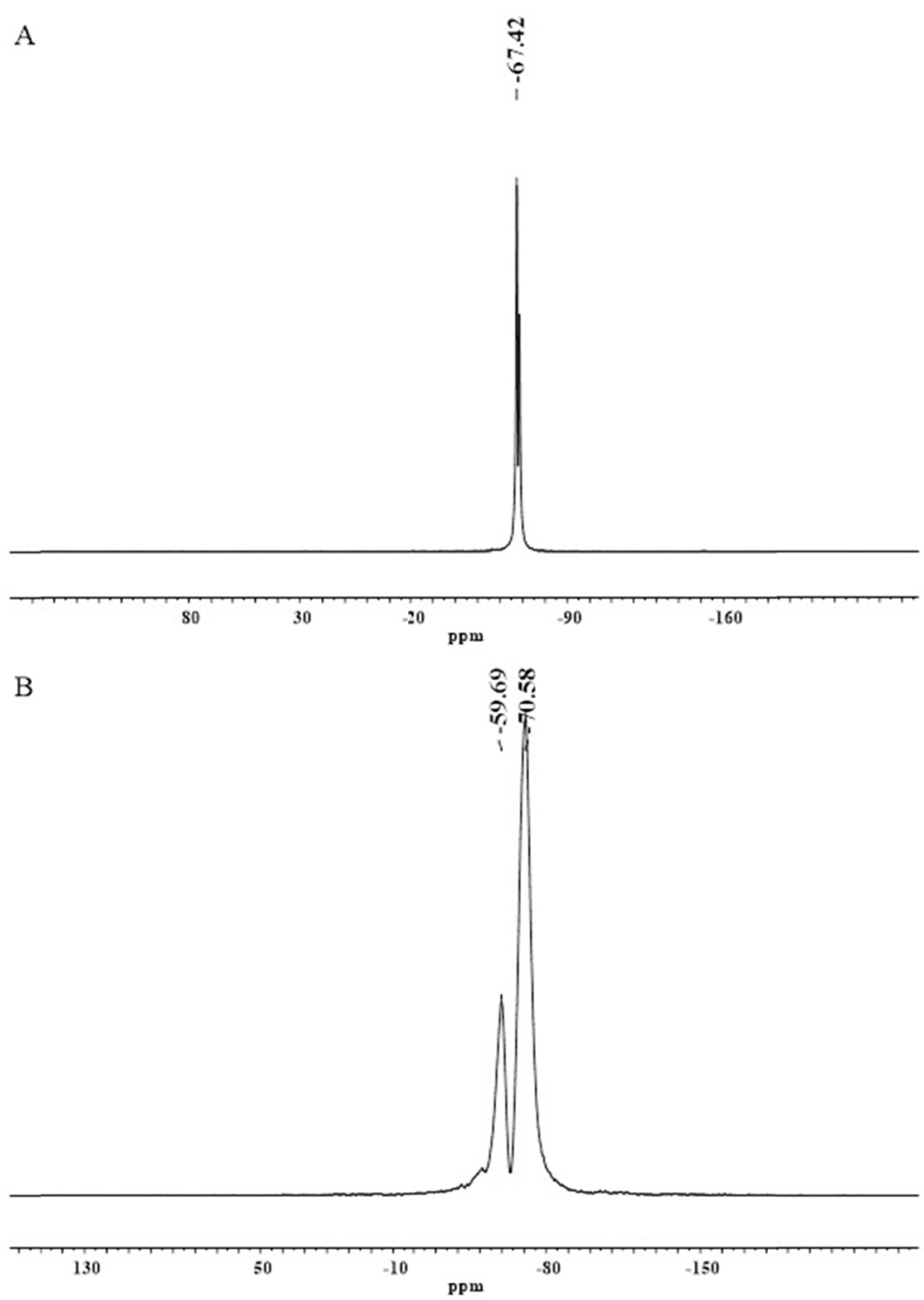

Figure 5. Solid state NMR of ${ }^{29} \mathrm{Si}$ for SS (A) and SSI (B)

\subsection{Voltammetric Characterization of AgHSSI}

The voltammetric characterization was conducted using the cyclic voltammetry technique using a typical electrochemical system consisting of three electrodes, an auxiliary platinum electrode, and one for reference $\left(\mathrm{Ag} / \mathrm{AgCl}_{(\mathrm{s})}\right)$, where the working electrode was a graphite paste electrode modified with AgHSSI (or AgSSI).

The AgSSI system was studied first, followed by the AgHSSI system. Figure 6(A) illustrates the cyclic voltammogram of AgSSI obtained from a graphite paste $(50 \% \mathrm{~m} / \mathrm{m})$. The voltammogram exhibited a redox couple with average potential $\left(\mathrm{E}^{\theta^{\prime}}\right)$ of $0.01 \mathrm{~V}$, attributed to the $\mathrm{Ag}^{0} / \mathrm{Ag}^{+}$redox process. Figure 6(B) illustrates the cyclic voltammogram of AgHSSI, obtained from a graphite paste electrode modified with AgHSSI $(50 \% \mathrm{~m} / \mathrm{m})$. The voltammogram exhibited a single redox couple, much wider and with $\mathrm{E}^{\theta^{\prime}}=0.14 \mathrm{~V}$, attributed to the $\mathrm{Fe}^{2+}(\mathrm{CN})_{6} /$ $\mathrm{Fe}^{3+}(\mathrm{CN})_{6}$ process. 


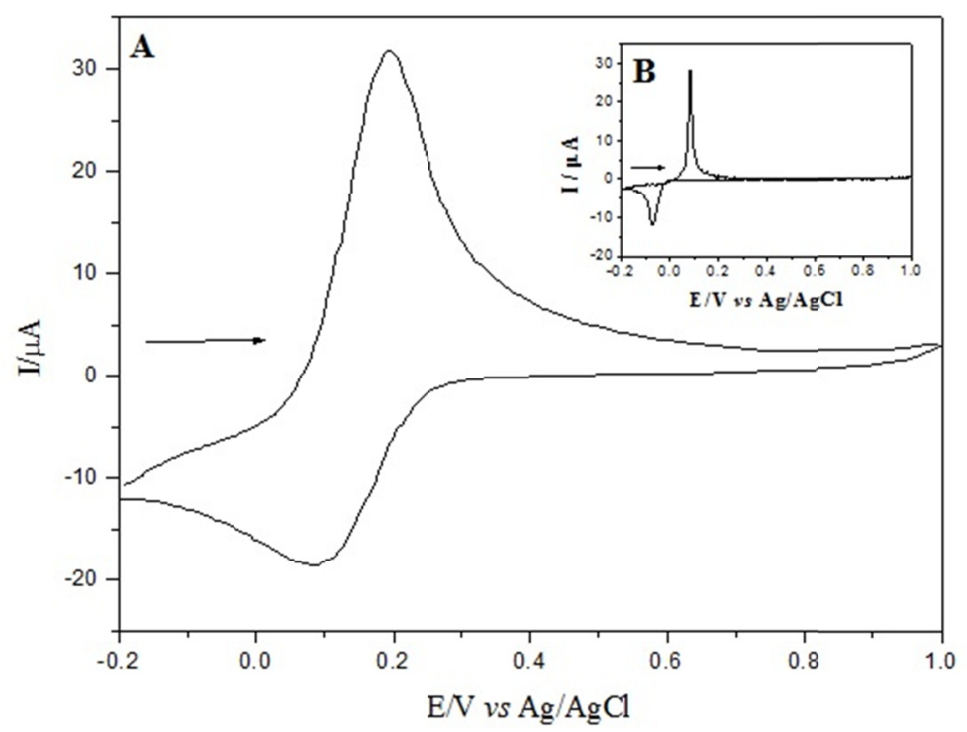

Figure 6. Cyclic voltammograms of (A) AgSSI $\left(\mathrm{KNO}_{3} 1.0 \mathrm{~mol} \mathrm{~L}^{-1}, v=20 \mathrm{mVs}^{-1}, 50 \% \mathrm{~m} / \mathrm{m}\right)$ and (B) AgHSSI $\left(\mathrm{KNO}_{3} 1.0 \mathrm{~mol} \mathrm{~L}^{-1}, v=20 \mathrm{mVs}^{-1}, 50 \% \mathrm{~m} / \mathrm{m}\right)$

\subsection{Study of the Effect of Cations and Anions}

A study was conducted regarding the influence of cations and anions from the supporting electrolyte on the voltammetric behavior of AgHSSI.

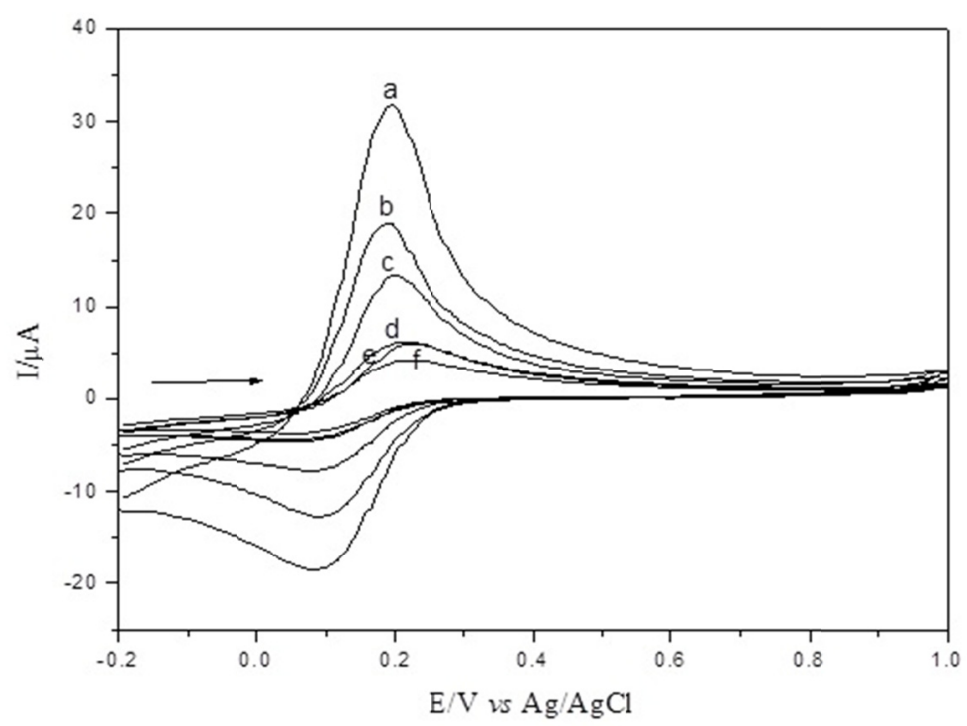

Figure 7. Cyclic voltammograms of the graphite paste modified with AgHSSI in different electrolytes $(v=20 \mathrm{mV}$ $\mathrm{s}^{-1}, 1.0 \mathrm{~mol} \mathrm{~L}-1,50 \% \mathrm{~m} / \mathrm{m}$ ): a) $\mathrm{KNO}_{3}$, b) $\mathrm{NaNO}_{3}$, c) $\mathrm{NH}_{4} \mathrm{Cl}$, d) $\mathrm{KCl}$, e) $\mathrm{LiCl}$, f) $\mathrm{NaCl}$

Different supporting electrolytes were tested, such as $\mathrm{KCl}, \mathrm{NaCl}, \mathrm{LiCl}, \mathrm{NH}_{4} \mathrm{Cl}, \mathrm{KNO}_{3}$ and $\mathrm{NaNO}_{3}\left(1.0 \mathrm{~mol} \mathrm{~L}^{-1}\right.$ and $\left.v=20 \mathrm{mVs}^{-1}\right)$. It was observed that the nature of the cations did not affect the $\mathrm{E}^{\theta^{\prime}}$ but the current intensities were decisively modified, as shown in Figure 7. It was found that in the presence of electrolytes containing the nitrate anion $\left(\mathrm{NO}_{3}^{-}\right)$the current intensities were higher than those obtained in the presence of electrolytes containing chloride $\left(\mathrm{Cl}^{-}\right)$. It was also observed that even in the presence of electrolytes containing chloride $\left(\mathrm{Cl}^{-}\right)$ there was no disappearance or inhibition of the redox process, also suggesting here that no silver chloride film $(\mathrm{AgCl})$ was formed on the electrode surface. Additionally, these studies also indicate that there was no formation of a crystalline lattice for AgHSSI. It was also observed that the Ipa/Ipc ratio varied from $\sim 1.4$ to 1.9 and $\Delta \mathrm{Ep}$ 
from 100 to $170 \mathrm{mV}$, for the supporting electrolytes, which suggests that the $\mathrm{Fe}^{2+}(\mathrm{CN})_{6} / \mathrm{Fe}^{3+}(\mathrm{CN})_{6}$ process is almost reversible. Figure 7 shows the voltammogram of the graphite paste modified with AgHSSI in different electrolytes.

Table 1 lists the main electrochemical parameters obtained from the cyclic voltammograms of the graphite paste modified with AgHSSI in different electrolytes.

Table 1. Electrochemical parameters of the graphite paste modified with AgHSSI in different electrolytes $(v=20$ $\left.\mathrm{mV} \mathrm{s}^{-1}, 1.0 \mathrm{~mol} \mathrm{~L}{ }^{-1}, 50 \% \mathrm{~m} / \mathrm{m}\right)$

\begin{tabular}{cccc}
\hline Electrolyte & $|\mathrm{Ipa} / \mathrm{Ipc}|$ & $\mathrm{E}^{\theta^{\prime}}(\mathrm{V})$ & $\Delta \mathrm{Ep}(\mathrm{V})$ \\
\hline $\mathrm{KCl}$ & 1.51 & 0.14 & 0.15 \\
$\mathrm{NaCl}$ & 1.39 & 0.14 & 0.16 \\
$\mathrm{LiCl}$ & 1.58 & 0.15 & 0.17 \\
$\mathrm{NH}_{4} \mathrm{Cl}$ & 1.89 & 0.15 & 0.11 \\
$\mathrm{KNO}_{3}$ & 1.77 & 0.14 & 0.11 \\
$\mathrm{NaNO}_{3}$ & 1.59 & 0.14 & 0.10 \\
\hline
\end{tabular}

It was found that although the voltammetric performance of AgHSSI is similar in all electrolytes tested, there were differences in the electrochemical parameters, especially in the potential variation $(\Delta \mathrm{Ep}) . \mathrm{E}^{\theta}$ remained practically constant, suggesting no binuclear complex was formed, however there was an electrostatic interaction between the imidazole and the hexacyanoferrate ion (cation) $\left[\mathrm{Fe}(\mathrm{CN})_{6}\right]^{3-}$, where the transition metal, the silver, acts as a proton attached to the imidazole N site (Hwang et al., 2008; Bard \& Faulkner, 1980).

For subsequent studies, $\mathrm{KNO}_{3}$ was chosen as supporting electrolyte due to its better voltammetric performance.

\subsection{Influence of Supporting Electrolyte Concentrations}

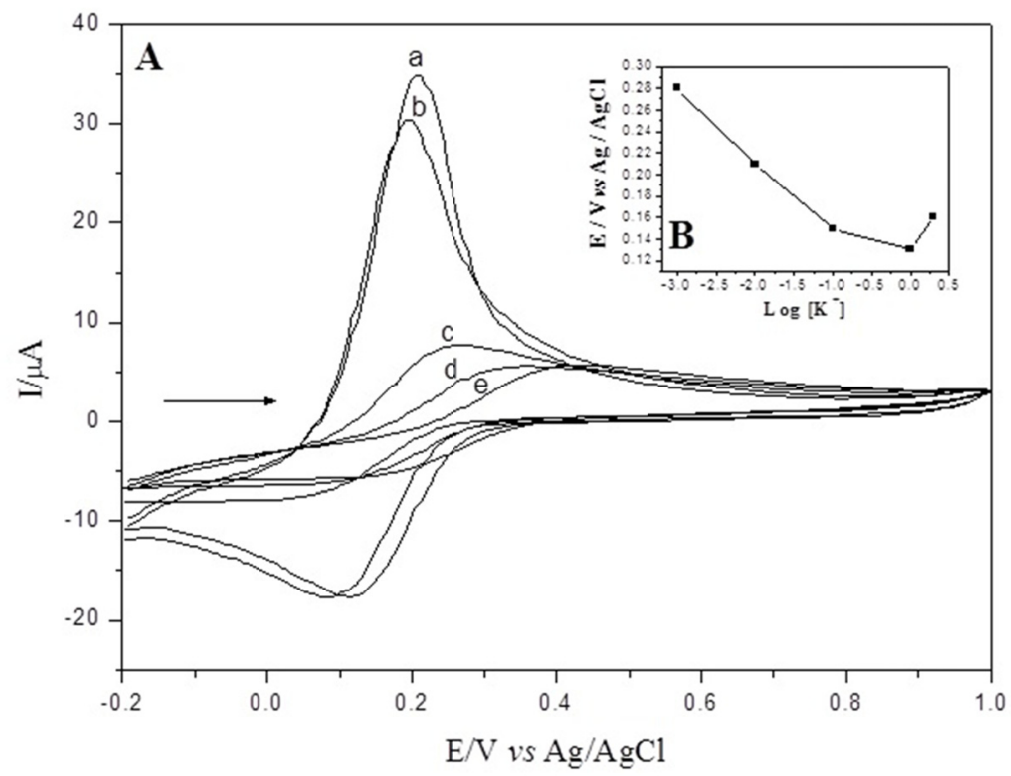

Figure 8. (A) Cyclic voltammograms of the graphite paste modified with AgHSSI at different concentrations of $\mathrm{KNO}_{3}\left(v=20 \mathrm{mVs}^{-1}, 50 \% \mathrm{~m} / \mathrm{m}\right)$ : a) $2 \mathrm{~mol} / \mathrm{L}^{-1}$, b) $1 \mathrm{~mol} / \mathrm{L}^{-1}$, c) $0.1 \mathrm{~mol} / \mathrm{L}^{-1}$, d) $0.01 \mathrm{~mol} / \mathrm{L}^{-1}$, e) $0.001 \mathrm{~mol} / \mathrm{L}^{-1}$ and (B) average potential $\left(\mathrm{E}^{\theta^{\prime}}\right)$ of the graphite paste modified with AgHSSI as a function of the log concentration of $\mathrm{KNO}_{3}\left(v=20 \mathrm{mVs}^{-1}, 50 \% \mathrm{~m} / \mathrm{m}\right)$

Figure 8(A) shows the cyclic voltammograms of the graphite paste modified with AgHSSI at different concentrations of $\mathrm{KNO}_{3}\left(0.001 \mathrm{~mol} \mathrm{~L}^{-1}\right.$ to $\left.2.0 \mathrm{~mol} \mathrm{~L}^{-1}\right)$. This study was not performed for AgSSI for the reason 
mentioned in the previous item.

Figure 8(B) shows the relationship between the average potential and the logarithm (log) of the $\mathrm{K}^{+}$concentration did not show a linear relationship, but the redox process is dependent on the concentration of $\mathrm{K}^{+}$.

After this study, the concentration of the supporting electrolyte $\left(\mathrm{KNO}_{3}\right)$ chosen to continue the subsequent studies was of $1.0 \mathrm{~mol} \mathrm{~L}^{-1}$ due to a better voltammetric performance.

\subsection{Study of the Effect of Different Hydrogen Ion Concentrations}

Figure 9 (A) shows the studies of the effect of different hydrogen ion concentrations (pH 2.0 to 8.0) on AgSSI and AgHSSI. Figure 9(B) shows the cyclic voltammograms of the relationship of AgSSI and the graph of the relation Ipa $v s \mathrm{pH}$, respectively. It was found that with an increase in $\mathrm{pH}$ there is an increase in the current intensity, varying anodic current values between 13.36 and $27.41 \mu \mathrm{A}$, and $\mathrm{E}^{\theta^{\prime}}$ kept constant at around zero.

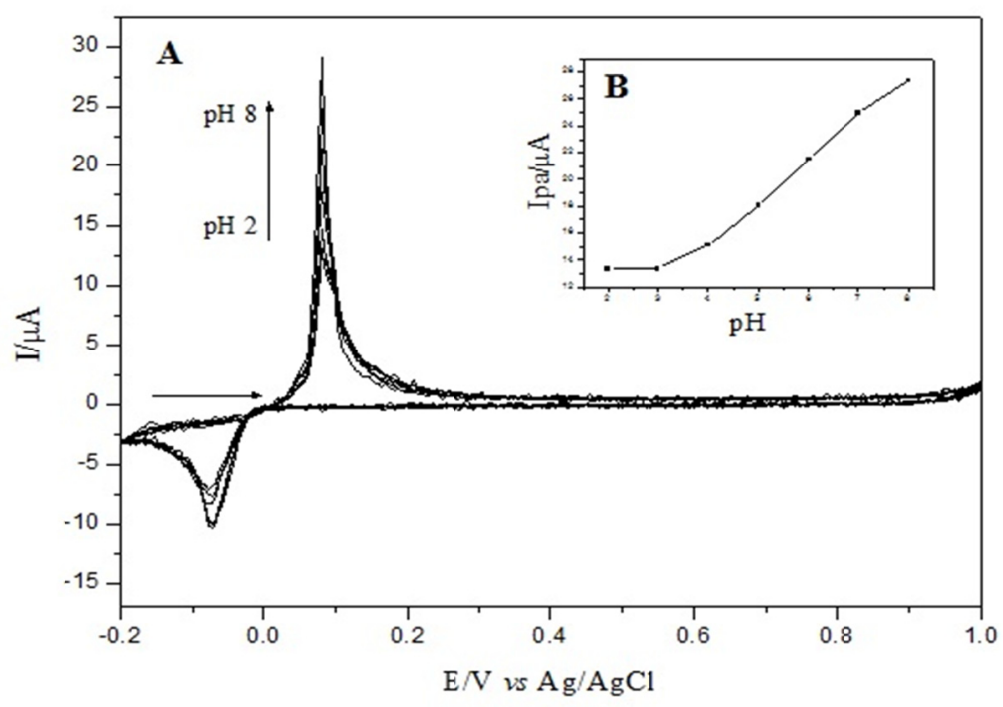

Figure 9. (A) Cyclic voltammograms of the graphite paste modified with AgSSI at different $\mathrm{pH}$ values (2.0 to 8.0); (B) Dependence on the current intensity of the graphite paste modified with AgSSI at different $\mathrm{pH}$ values $\left(\mathrm{KNO}_{3}\right.$ $\left.1.0 \mathrm{~mol} \mathrm{~L}^{-1}, v=20 \mathrm{mV} \mathrm{s}^{-1}, 50 \% \mathrm{~m} / \mathrm{m}\right)$

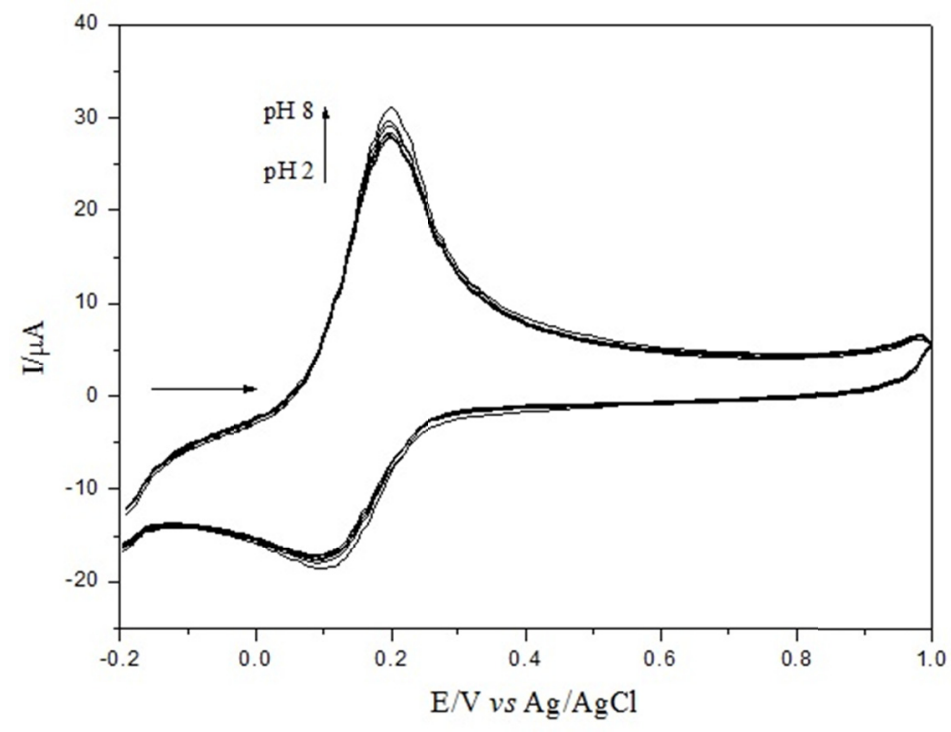

Figure 10. Cyclic voltammograms of the graphite paste modified with AgHSSI at different $\mathrm{pH}$ values (2.0 to 8.0); $\left(\mathrm{KNO}_{3} 1.0 \mathrm{~mol} \mathrm{~L}{ }^{-1}, v=20 \mathrm{mV} \mathrm{s}^{-1}, 50 \% \mathrm{~m} / \mathrm{m}\right)$ 
Figure 10 illustrates the voltammograms corresponding to AgHSSI. These results showed that the $\mathrm{pH}$ variation did not significantly affect the electrochemical parameters. The anodic current values ranged between 23.73 and $27.05 \mu \mathrm{A}$ and $\mathrm{E}^{\theta^{\prime}}$ values remained between 0.14 and $0.15 \mathrm{~V}$.

As no significant changes occurred with regards to the change in $\mathrm{pH}$, the value chosen for future studies was 7.0, due to the fact that future studies will be performed for the electrocatalytic determination of drugs in biological $\mathrm{pH}$ studies.

\subsection{Influence of Scan Rates}

The scan rate influence was studied for both systems (AgSSI and AgHSSI). Figure 11(A) shows the cyclic voltammograms of AgSSI at different scan rates $\left(10\right.$ to $\left.100 \mathrm{mV} \mathrm{s}^{-1}\right)$. It was found that with increased scan rate there is an increase in the current intensity, but at $30 \mathrm{mV} \mathrm{s}^{-1}$ there is no increase in the current intensity, but rather the detection of other species in more anodic oxidation potential, suggesting that the oxidation and reduction processes are kinetically faster. It is known that imidazole can form two species with $\mathrm{Ag}(\mathrm{I})$, namely, $\mathrm{Ag}\left[\mathrm{C}_{3} \mathrm{~N}_{2} \mathrm{H}_{4}\right]^{+}$ and $\mathrm{Ag}\left[\mathrm{C}_{3} \mathrm{~N}_{2} \mathrm{H}_{4}\right]_{2}^{+2}$ potentiometrically evidenced (Baumxn \& Wasg, 1964) with the latter as the most stable form. The $\mathrm{E}^{\theta^{\prime}}$ of the first process remained between zero and $0.01 \mathrm{~V}$. When this study was conducted in a broader potential range ( -0.4 to $1.0 \mathrm{~V})$, the presence of these species was more noticeable.

Figure 11(B) illustrates the linear dependency between the current intensity of the anodic/cathodic peak and the square root of the scan rate in the range of 10 to $30 \mathrm{mV} \mathrm{s}^{-1}$, characterizing a diffusional process [42], and thereafter the intensity current remains constant.

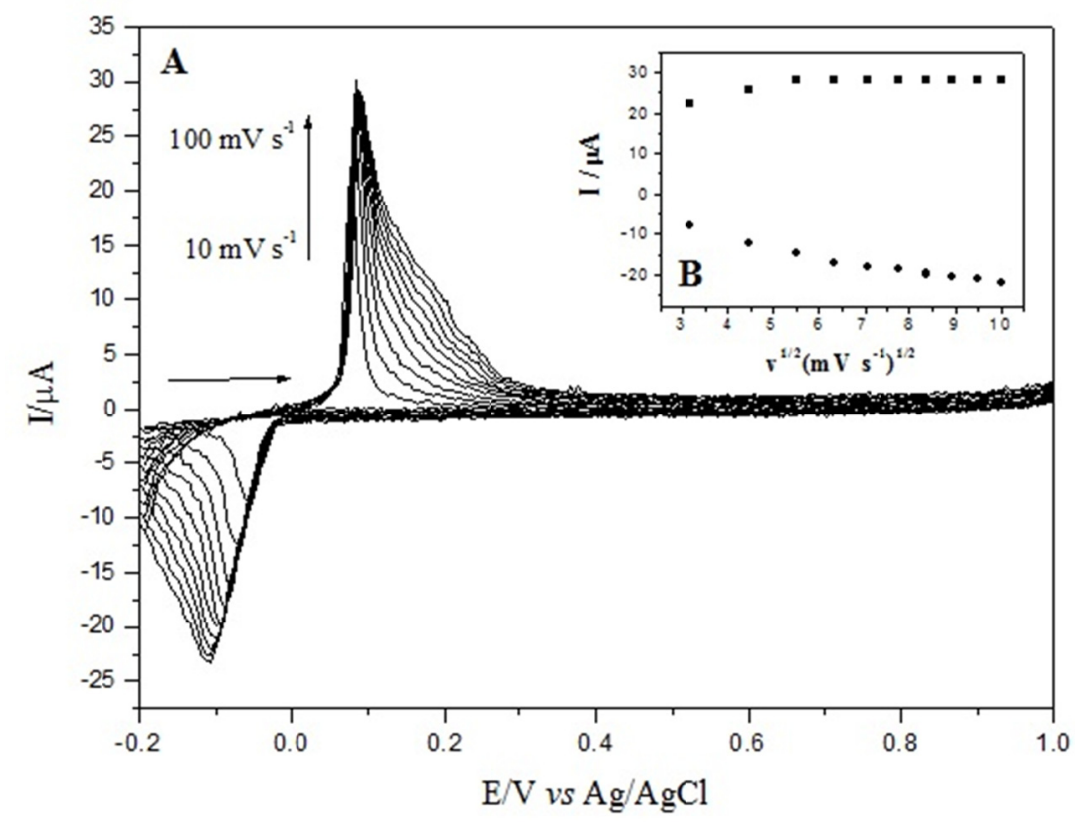

Figure 11. (A) Cyclic voltammograms of the graphite paste modified with AgSSI at different scan rates $\left(\mathrm{KNO}_{3} 1.0\right.$ $\mathrm{mol} \mathrm{L}{ }^{-1}, \mathrm{pH} 7,50 \% \mathrm{~m} / \mathrm{m}$ )and (B) dependence of anodic and cathodic peak current intensity on the square root of the scan rate

Figure 12(A) shows the cyclic voltammograms of AgHSSI at different scan rates (10 to $\left.100 \mathrm{mV} \mathrm{s}^{-1}\right)$. It was found that with increased rate there is an increase in the current intensity and $\mathrm{E}^{\theta^{\prime}}$ remained between 0.14 and $0.15 \mathrm{~V}$. With the rate increase only one species was detected in the AgSSI system, however the oxidation potential shifted slightly to more positive potential regions (anodic region).

Figure 12(B) shows the linear dependence between the current intensity of the anodic/cathode peak and the square root of the scan rate for AgHSSI, characterizing a diffusional process (Bard \& Faulkner, 1980). 


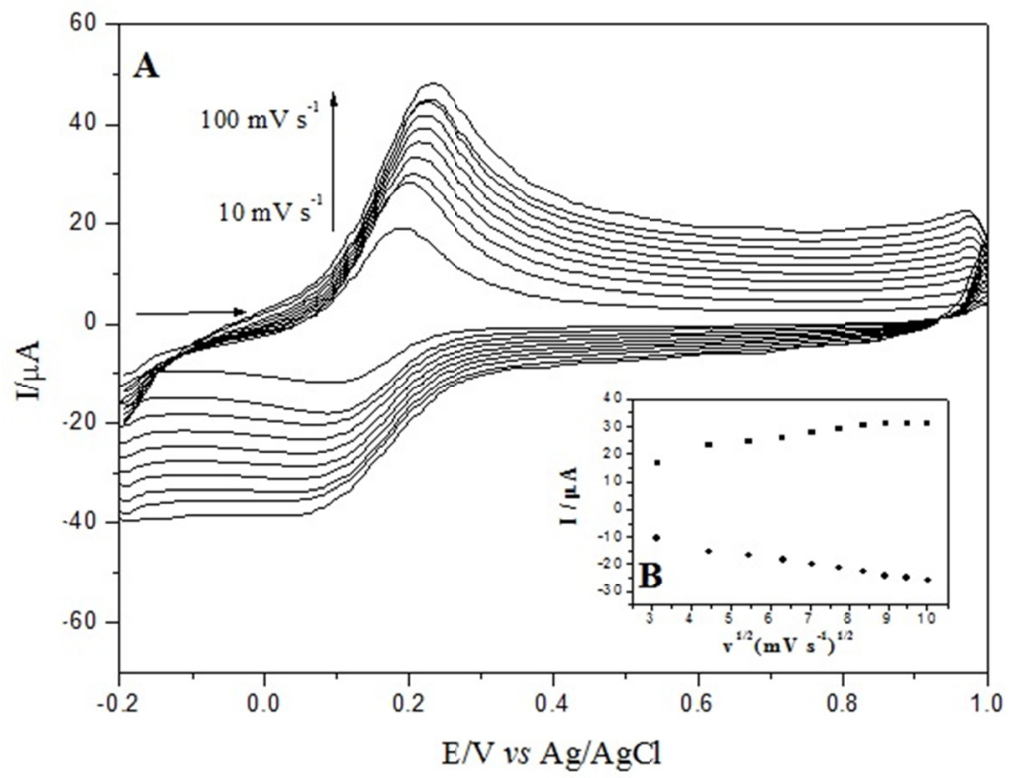

Figure 12. (A) Cyclic voltammograms of the graphite modified with AgHSSI at different scan rates $\left(\mathrm{KNO}_{3} 1.0\right.$ $\mathrm{mol} \mathrm{L}^{-1}, \mathrm{pH} 7,50 \% \mathrm{~m} / \mathrm{m}$ ) and (B) dependence of anodic and cathodic peak current intensity on the square root of the scan rate

\section{Conclusions}

Synthesis of octa-(3-chloropropyl)octasilsesquioxane (SS) and functionalization thereof with the ligand imidazole (SSI) were performed with success. The characterization and cyclic voltammetry studies shown, the freshly prepared materials, AgHSSI, has no characteristics for an intervalence or mixed valence complex, which has a crystal lattice that is highly dependent on the input and output of cations to maintain its electroneutrality. This is probably due to the action of AgSSI as a cation. The interaction was purely electrostatic between the AgSSI and the potassium hexacyanoferrate (III) material.

\section{Acknowledgments}

Financial support for this research was supplied by Fundação de Amparo à Pesquisa do Estado de São Paulo (FAPESP - Processes: 2012/05438-1, 2003/12882-6, 2013/08495-9), Conselho Nacional de Desenvolvimento Científico e Tecnológico (CNPq) Processe. 306087/2012-0 and the Coordenação de Aperfeiçoamento de Pessoal de Nível Superior (CAPES).

\section{References}

Aany Sofia, L. T., Krishnan, A., Sankar, M., Kala Raj, N. K., Manikandan, P., Rajamohanan, P. R., \& Ajithkumar, T. G. (2009). Immobilization of phosphotungstic acid (PTA) on imidazole functionalized silica: Evidence for the nature of PTA binding by solid state NMR and reaction studies. Journal of Physical Chemistry C, 113, 21114-21122. http://dx.doi.org/10.1021/jp906108e

Abbenhuis, H. C. L. (2000). Advances in homogenous and heterogenous catalysis with metal - containing silsesquioxanes. Chemistry $\quad-A$ European Journal, $6, \quad$ 25-32. http://dx.doi.org/10.1002/(SICI)1521-3765(20000103)6:1<25::AID-CHEM25>3.0.CO;2-Y

Bard, A. J., \& Faulkner, L. R. (1980). Electrochemical Methods. New York, NY: John Wiley \& Sons.

Bassindale, A. R., Codina-Barrios, A., Frascione, N., \& Taylor, P. G. (2008). The use of silsesquioxane cages and phage display technology to probe silicone-protein interactions. New Journal of Chemistry, 32, 240-246. http://dx.doi.org/10.1039/B710984A

Baumxn Jr., E., \& Wasg, J. C. (1964). Imidazole Complexes of Nickel(II), Copper(II), Zinc(II) and Silver(I). Inorganic Chemistry, 3, 368-373. http://dx.doi.org/10.1021/ic50013a014

Chojnowski, J., Fortuniak, W., Rościszewski, P., Werel, W., Łukasiak, J., Kamysz, W., \& Hałasa, R. (2006). Polysilsesquioxanes and oligosilsesquioxanes substituted by alkylammonium salts as antibacterial biocides.

Journal of Inorganic and Organometallic Polymers and Materials, 16, 219-230. 
http://dx.doi.org/10.1007/s10904-006-9048-5

Cordes, D. B., Lickiss, P. D., \& Rataboul, F. (2010). Recent developments in the chemistry of cubic polyhedral oligosilsesquioxanes. Chemistry Review, 110, 2081-2173. http://dx.doi.org/10.1021/cr900201r

Devaux, E., Rochery, M., \& Bourbigot, S. (2002). Polyurethane/clay and polyurethane/POSS nanocomposites as flame retarded coating for polyester and cotton fabrics. Fire Materials, 26, 149-154. http://dx.doi.org/10.1002/fam.792

Do Carmo, D. R. do, Paim, L. L., Dias Filho, N. L., \& Stradiotto, N. R. (2007). Preparation, characterization and application of a nanostructure composite: Octakis (cyanopropyldimethylsiloxy) octasilsesquioxane. Applied Surface Science, 253, 3683-3689. http://dx.doi.org/10.1016/j.apsusc.2006.07.080

Dutkiewicz, M., Maciejewski, H., \& Marciniec, B. (2009). Functionalization of Polyhedral Oligomeric Silsesquioxane (POSS) via nucleophilic substitution - Paper. Synthesis, 1, 2019-2024. http://dx.doi.org/10.1055/s-0029-1216807

Figgis, B. N., \& Hitchman, M. A. (2000). Ligand Field Theory and Its Applications. New York, NY: Wiley.

Fina, A., Tabuani, D., Carniato, F., Frache, A., Boccaleri, E., \& Camino, G. (2006). Polyhedral Oligomeric Silsesquioxanes (POSS) thermal degradation. Thermochimica Acta, 440, 36-42. http://dx.doi.org/10.1016/j.tca.2005.10.006

Gnanasekaran, D., Madhavan, K., \& Reddy, B. S. R. (2009). Developments of polyhedral oligomericsil Sesquioxanes (POSS). POSS nanocomposites and their applications: A review. Journal of Scientific \& Industrial Research, 68, 437-464.

Henderson, W. W., Shepherd, R. E., \& Abolaf, J. (1986). ${ }^{1} \mathrm{H}$ and ${ }^{13} \mathrm{C}$ NMR Spectra of a series of methyl-substituted imidazole complexes of pentaamminecobalt(II1) and crystal structure of the remote isomer of [(4-Methylimidazole)pentaamminecobalt(111)] trichloridedihydrate. Inorganic Chemistry, 25, 3157-3163.

Hwang, S., Lee, B. S., Chi, Y. S., Kwak, J., Choi, I. S., \& Lee, S. (2008). Faradaic impedance titration and control of electron transfer of 1-(12-mercaptododecyl)imidazole monolayer on a gold electrode. Electrochimica Acta, 53, 2630-2636. http://dx.doi.org/10.1016/j.electacta.2007.10.043

Joseph, A., Ramamurthy, P. C., \& Subramanian, S. (2011). Imidazole functionalized polyaniline: Synthesis, characterization, and $\mathrm{Cu}(\mathrm{II})$ coordination studies. Journal of Applied Polymer Science, 123, 526-534. http://dx.doi.org/10.1002/app.34561

Lickiss, P. D., \& Rataboul, F. (2008). Chapter 1: Fully condensed polyhedral oligosilsesquioxanes (POSS): from synthesis to application. Advances in Organometallic Chemistry, 57, 1-116. http://dx.doi.org/10.1016/S0065-3055(08)00001-4

Lin, T. H., \& Chen, W. Z. (2010). Photo-alignment effect in liquid-crystal films containing nanoparticles and azo-dye. Key Engineering Materials, 276-279. http://dx.doi.org/10.1063/1.3142390

Lu, T. L., Liang, G. Z., \& Kou, K. G. (2005). Review: Synthesis and characterization of cage octa (cyclohexysilsesquioxane). Journal of Materials Science, 40, 4721-4726. http://dx.doi.org/10.1007/s10853-005-0839-9

Marciniec, B., Dutkiewicz, M., Maciejewski, H., \& Kubicki, M. (2008). New effective method of synthesis and structural characterization of octakis (3-chloropropyl) octasilsesquioxane. Organometallics, 27, 793-794. http://dx.doi.org/10.1021/om700962x

Morán, M., Casado, C. M., \& Cuadrado, I. (1993). Ferroceny substituted octakis (dimethylsiloxy)octasilsesquioxanes: A new class of supramolecular organometallic compounds. Synthesis, $\begin{array}{llll}\text { characterization, and electrochemistry. } & \text { Organometallics, } & 12, & \text { 4327-4333. }\end{array}$ http://dx.doi.org/10.1021/om00035a018

Phillips, S. H., Haddad, T. S., \& Tomczak, S. J. (2004). Developments in nanoscience polyhedral oligomericsilsesquioxane (POSS) - polymers. Current Opinion in Solid State - Materials Science, 8, 21-29. http://dx.doi.org/10.1016/j.cossms.2004.03.002

Pielichowski, K., Njuguna, J., Janowski, B., \& Pielichowski, J. (2006). Polyhedral oligomericsil sesquioxanes (POSS) - containgnanohybrid polymers. Advances in Polymer Science, 201, 225-296. http://dx.doi.org/10.1007/12_077 
Rajec, P., \& Hanzel, R. (2003). Sorption of cobalt on modified silica gel materials. Czechoslovak Journal of Physics, 53, 525-531. http://dx.doi.org/10.1007/s10582-003-0067-y

Ro, H. W., Park, E. S., Soles, C. L., \& Yoon, D. Y. (2010). Structure - property relation - ships for methylsilsesquioxanes. Chemistry of Materials, 22, 1330-1339. http://dx.doi.org/10.1021/cm901771y

Ropartz, L., Morris, R. E., Foster, D. F., \& Cole-Hamilton, D. J. (2002). Phosphine containgcarbosilanedendrimers based on polyhedral silsesquioxane cores as ligands for hydroformylation reaction of oct-1-ene. Journal of Molecular Catalysis A: Chemical, 182-183, 99-105. http://dx.doi.org/10.1016/S1381-1169(01)00502-7

Silveira, T. F. S. da, Silvestrini, D. R., Bicalho, U. O., \& Do Carmo, D. R. (2013). Voltammetric study of a cubic silsesquioxane organically modified with imidazole and their subsequent reaction with cadmium and hexacyanoferrate (III). International Journal of Electrochemical Science, 8, 872-886.

Silveira, T. F. S. da. (2012). Potencialidade analítica de um silsesquioxano e uma sílica organofuncionalizados com imidazol. Dissertação (Mestrado) - Faculdade de Engenharia, Universidade Estadual Paulista "Júlio de Mesquita Filho", Ilha Solteira, 2012.

Silverstein, R. M., \& Welbster, F. X. (1996). Spectrometric identification of organic compounds (6th ed.). New York, NY: John Wiley \& Sons.

Skaria, S., \& Schricker, S. R. (2010). Synthesis and characterization of Inorganic - Organic Hybrid Materials derived from polysilsesquioxanes (POSS). Journal of Macromolecular Science part A, 47, 381-391. http://dx.doi.org/10.1080/10601321003659440

Voronkov, M. G., \& Lavrent'yev, V. L. (1982). Polyhedraloligosilsesquioxanes and their homo derivates. Topics in Current Chemistry, 102, 199-236. http://dx.doi.org/10.1007/3-540-11345-2_12

Wann, D. A., Less, J. R., Rataboul, F., McCaffrey, P. D., Reilly, A. M., Robertson, H. E., ... Rankin, D. W. H. (2008). Accurate gas-phase experimental structures of octasilsesquioxanes $\left(\mathrm{Si}_{8} \mathrm{O}_{12} \mathrm{X}_{8} ; \mathrm{X}=\mathrm{H}, \mathrm{Me}\right)$. Organometallics, 27, 4183-4187. http://dx.doi.org/10.1021/om800357t

Yin, P., Xu, Q., Qu, R., Zhao, G., \& Sun, Y. (2010). Adsorption of transition metal ions from aqueous solutions onto a novel silica gel matrix inorganic-organic composite material. Journal of Hazardous Materials, 173, 710-716. http://dx.doi.org/10.1016/j.jhazmat.2009.08.143

\section{Copyrights}

Copyright for this article is retained by the author(s), with first publication rights granted to the journal.

This is an open-access article distributed under the terms and conditions of the Creative Commons Attribution license (http://creativecommons.org/licenses/by/3.0/). 